\title{
Reporting Source Type Code
}

National Cancer Institute

\section{Source}

National Cancer Institute. Reporting Source Type Code. NCI Thesaurus. Code C154672.

A coded value specifying the kind of medical record that provided the best information when abstracting the relevant healthcare data. 